OPEN ACCESS

Edited by:

Ahmed M. Abdel-Azeem,

Suez Canal University, Egypt

Reviewed by:

Muniaraj Mayilsamy,

Vector Control Research Centre

(ICMR), India

Aunchalee Thanwisai,

Naresuan University, Thailand

Elsiddig Noureldin,

Saudi Center for Disease Control and Prevention (CDC), Saudi Arabia

*Correspondence: Marta Rodrigues de Oliveira moliveirabiotec@gmail.com Antonia Queiroz Lima de Souza antoniaqueiroz@ufam.edu.br

t'In memoriam

Specialty section:

This article was submitted to

Microbiotechnology,

a section of the journal

Frontiers in Microbiology

Received: 17 July 2021 Accepted: 28 October 2021 Published: 10 December 2021

Citation:

de Oliveira MR, Katak RM, da Silva GF, Marinotti O, Terenius O,

Tadei WP, de Souza ADL and de

Souza AQL (2021) Extracts of Amazonian Fungi With Larvicidal

Activities Against Aedes aegypti.

Front. Microbiol. 12:743246.

doi: 10.3389/fmicb.2021.743246

\section{Extracts of Amazonian Fungi With Larvicidal Activities Against Aedes aegypti}

\author{
Marta Rodrigues de Oliveira ${ }^{1 *}$, Ricardo de Melo Katak², Gilvan Ferreira da Silva ${ }^{3}$, \\ Osvaldo Marinotti ${ }^{4}$, Olle Terenius ${ }^{5}$, Wanderli Pedro Tadei ${ }^{1,2,6+}$, \\ Afonso Duarte Leão de Souza ${ }^{1,7,8}$ and Antonia Queiroz Lima de Souza ${ }^{1,7,9 *}$
}

\begin{abstract}
${ }^{1}$ Programa de Pós-graduação em Biodiversidade e Biotecnologia (PPG-BIONORTE), Universidade Federal do Amazonas, Manaus, Brazil, ${ }^{2}$ Programa de Pós-graduação em Biotecnologia, Universidade Federal do Amazonas, Manaus, Brazil, ${ }^{3}$ Embrapa Amazônia Ocidental, Manaus, Brazil, ${ }^{4}$ MTEKPrime, Aliso Viejo, CA, United States, ${ }^{5}$ Department of Cell and Molecular Biology, Microbiology, Uppsala University, Uppsala, Sweden, ${ }^{6}$ Laboratório de Malária e Dengue, Instituto Nacional de Pesquisas da Amazônia, Manaus, Brazil, ${ }^{7}$ Central Analítica - Centro de Apoio Multidisciplinar, Universidade Federal do Amazonas, Manaus, Brazil, ${ }^{8}$ Departamento de Química, Universidade Federal do Amazonas, Manaus, Brazil,

${ }^{9}$ Faculdade de Ciências Agrárias, Universidade Federal do Amazonas, Manaus, Brazil
\end{abstract}

The global increase in diseases transmitted by the vector Aedes aegypti, new and re-emerging, underscores the need for alternative and more effective methods of controlling mosquitoes. Our aim was to identify fungal strains from the Amazon rain forest that produce metabolites with larvicidal activity against Aedes aegypti. Thirty-six fungal strains belonging to 23 different genera of fungi, isolated from water samples collected in the state of Amazonas, Brazil were cultivated. The liquid medium was separated from the mycelium by filtration. Medium fractions were extracted with ethyl acetate and isopropanol 9:1 volume:volume, and the mycelia with ethyl acetate and methanol 1:1. The extracts were vacuum dried and the larvicidal activity was evaluated in selective bioassays containing $500 \mu \mathrm{g} / \mathrm{ml}$ of the dried fungal extracts. Larval mortality was evaluated up to $72 \mathrm{~h}$. None of the mycelium extracts showed larvicidal activity greater than $50 \%$ at $72 \mathrm{~h}$. In contrast, 15 culture medium extracts had larvicidal activity equal to or greater than $50 \%$ and eight killed more than $90 \%$ of the larvae within $72 \mathrm{~h}$. These eight extracts from fungi belonging to seven different genera (Aspergillus, Cladosporium, Trichoderma, Diaporthe, Albifimbria, Emmia, and Sarocladium) were selected for the determination of $\mathrm{LC}_{50}$ and $\mathrm{LC}_{90}$. Albifimbria lateralis (1160) medium extracts presented the lowest $L_{50}$ value $(0.268 \mu \mathrm{g} / \mathrm{ml})$ after $24 \mathrm{~h}$ exposure. Diaporthe ueckerae (1203) medium extracts presented the lowest value of LC90 $(2.928 \mu \mathrm{g} / \mathrm{ml})$ at $24 \mathrm{~h}$, the lowest values of $\mathrm{LC}_{50}(0.108 \mu \mathrm{g} / \mathrm{ml})$ and LC $90(0.894 \mu \mathrm{g} / \mathrm{ml})$ at $48 \mathrm{~h}$ and also at $72 \mathrm{~h}\left(\mathrm{LC}_{50}=0.062 \mu \mathrm{g} / \mathrm{ml}\right.$ and $\left.\mathrm{LC}_{90}=0.476 \mu \mathrm{g} / \mathrm{ml}\right)$. Extracts from Al. lateralis (1160) and D. ueckerae (1203) showed potential for developing new, naturally derived products, to be applied in integrated vector management programs against Ae. aegypti. 


\section{INTRODUCTION}

Aedes aegypti mosquitoes are the main vectors of arboviruses such as those that cause dengue, chikungunya, and Zika illnesses (Consoli and Oliveira, 1994; de Oliveira Barbosa Bitencourt et al., 2021). These diseases have occupied a prominent position in public health in several countries of the Americas, including Brazil where the occurrence of all these arboviruses has been recorded simultaneously since 2015 (Saúde and Saúde, 2016).

In 2014, chikungunya fever was first recorded in Brazil and spread rapidly throughout the country (Araújo et al., 2020). A short time later, Zika virus was detected in northeastern Brazil in 2015 (Possas et al., 2017). In 2016, the country reached a peak of cases, with more than 215 thousand estimated cases of Zika (Saúde and Saúde, 2018), which resulted in thousands of cases of neonatal microcephaly (Zanotto and Leite, 2018). Dengue is characterized as one of the main arboviruses with worldwide outbreaks occurring in the Americas, Africa, the Middle East, Asia, and the Pacific Islands. About 3.9 billion people in 129 countries are at risk of infection by the dengue virus, a notable increase from previous decades, partially explained by the improvement of records and recognition of the disease burden by governments (WHO, 2020). According to the Pan American Health Organization, the highest number of dengue cases ever reported globally was in 2019. Brazil alone reported about 2.2 million cases in 2019, representing 70\% of the total recorded in the Americas (PAHO, 2020).

Since specific antiviral drugs and effective vaccines against these arboviruses are not available, measures to curb the transmission of these diseases remain focused on vector control, mostly through the elimination of breeding sites and the use of chemical insecticides (Zara et al., 2016). However, the frequent use of chemical insecticides is toxic to the environment and has resulted in the selection of insecticide-resistant mosquito populations (Seetharaman et al., 2018; Araújo et al., 2020). It is therefore urgently necessary to explore new approaches to control these vectors.

Fungal secondary metabolites constitute a rich source of bioactive molecules (Daniel et al., 2017), potentially useful for mosquito control. More specifically, fungi isolated from aquatic habitats are a rich and unexplored source of new natural products. In order to adapt and survive in the aquatic environment, fungi accumulate unique bioactive secondary metabolites, not found in terrestrial environments (Bhakuni and Rawat, 2006; Imhoff, 2016).

The Amazon rainforest contains $\sim 25 \%$ of the world's terrestrial biodiversity (Malhi et al., 2008), including microorganisms potentially useful for $A$. aegypti control programs. In this work, we explored the larvicidal potential of the fungi isolated from the aquatic environments of the Amazon region. Our results suggest the possibility of utilizing fungiderived extracts and/or their metabolites as part of integrated vector management programs.

\section{MATERIALS AND METHODS}

\section{Production of the Fungal Extracts \\ Fungi Isolation and Identification}

Thirty-six fungi were isolated from water samples collected in the municipalities of Coari (muddy water) and São Gabriel da Cachoeira (black water), in the state of Amazonas, Brazil, using standard microbiological techniques. Water samples were collected at the following four sites: (a) Coari/C1 - dam $\left(4^{\circ} 06^{\prime}\right.$ $\left.43.7^{\prime \prime} \mathrm{S} 63^{\circ} 07^{\prime} 43.6^{\prime \prime} \mathrm{W}\right)$, (b) Coari/C2 - natural lake ( $4^{\circ} 06^{\prime}$ $56.6^{\prime \prime} \mathrm{S} 63^{\circ} 08^{\prime} 34.4^{\prime \prime} \mathrm{W}$ ), (c) São Gabriel da Cachoeira/S3 - fish farm $\left(0^{\circ} 6^{\prime} 54.873^{\prime \prime} \mathrm{S} 67^{\circ} 5^{\prime} 12.859^{\prime \prime} \mathrm{W}\right)$, and (d) São Gabriel da Cachoeira/S4 - natural lake $\left(0^{\circ} 7^{\prime} 6.866^{\prime \prime} \mathrm{S} 67^{\circ} 4^{\prime} 24.576^{\prime \prime}\right.$ W). Isolated fungi were preserved in glycerol $20 \%$, at $-80^{\circ} \mathrm{C}$ and stored in the collection of microorganisms of the Laboratory of Bioassays and Microorganisms of the Amazon at the Federal University of Amazonas (LabMicrA/UFAM). All fungi were registered in the Brazilian National System of Genetic Heritage Management and Associated Traditional Knowledge (SisGen) under the number AD64E07. The fungal strains were identified according to their unique deposit code in the LabMicrA/UFAM collection. Taxonomic identification of the strains was carried out in a previous study (Oliveira, 2021) and was based on the DNA sequences of the internal transcribed spacer region (ITS2) and macro- and micro morphological characters (Hanlin and Ulloa, 1988; Hawksworth et al., 1995; Dugan, 2006).

\section{Fungal Extract Preparation}

Each isolate was first inoculated in Petri dishes containing a PDA + L semi-solid culture medium (200 g/l potato, $20 \mathrm{~g} / \mathrm{l}$ dextrose and $15 \mathrm{~g} / \mathrm{l}$ agar and $2 \mathrm{~g} / \mathrm{l}$ yeast extract). Three fragments of the mycelium of the fungi (three-point inoculation) were sown at equidistant points and cultivated at $26^{\circ} \mathrm{C}$ for 8 days to confirm the purity of the preserved samples. Then a single fragment of each fungus was transferred into a new Petri dish (central point) containing the PDA $+\mathrm{L}$ medium and grown under the same conditions used previously. Then, five fragments of $1 \mathrm{~cm}^{2}$ of each fungus were inoculated in $300 \mathrm{ml}$ of PD + L liquid culture medium ( $200 \mathrm{~g} / \mathrm{l}$ potato, $20 \mathrm{~g} / \mathrm{l}$ dextrose, and $2 \mathrm{~g} / \mathrm{l}$ yeast extract) under sterile conditions (Souza et al., 2004). The samples were prepared in quintuplicate, including the media control and kept in static mode at $26^{\circ} \mathrm{C}$ in the absence of light.

Glucose and $\mathrm{pH}$ measurements of all samples were carried out every 3 days using test strips (Uriclin 10). The optimal time of cultivation of each strain was established as the time needed for total consumption of the glucose provided in the fresh medium. The cultured liquid medium was then vacuum filtered and separated from the mycelium. The culture liquid, totalizing a final volume of $1.1 \mathrm{l}$ for each fungus, was partitioned, so an organic mixture, immiscible with water, was required. The partitioning process was done in a separating funnel with a mixture of ethyl acetate (AcOEt) and isopropanol (iPr-OH) 9:1 volume/volume $(\mathrm{v} / \mathrm{v})$ three times, using each time $300 \mathrm{ml}$ of the solvent mixture. 
The mycelium extraction was an immersion process. The solvent mixture used polar and non-polarized directed metabolites. The mycelium fraction was soaked with a mixture of methanol (MeOH) and AcOEt 1:1 (v/v) for $48 \mathrm{~h}$ and was then filtered to obtain the first extract. The mycelium was soaked twice more for $24 \mathrm{~h}$ and the extracts were combined with the first one. Each liquid and mycelial extracts obtained were concentrated in a rotary evaporator $\left(\mathrm{Tecnal}^{\circledR}\right)$, under reduced pressure with a vacuum pump and at $45^{\circ} \mathrm{C}$. Dried extracts were weighed and stored in a desiccator with activated silica.

\section{Rearing Aedes aegypti}

Field collected Aedes aegypti eggs (F0) (Manaus, Brazil, February 2018) were placed in containers with water for hatching. The larvae were reared in a plastic tray containing distilled water, and the water was changed every 2 days. The larvae were fed daily with a mixture of rat food (Teklad Global 18\%) and cat food (Whiskas ${ }^{\circledR}$ ) at a ratio of $1: 1$ until they reached the pupal stage and were then transferred to plastic cups containing $50 \mathrm{ml}$ of water, which were placed in mosquito rearing cages $(30 \mathrm{~cm} \times 30 \mathrm{~cm} \times 30 \mathrm{~cm})$ for the emergence of adult mosquitoes. Aedes aegypti taxonomic identification was confirmed by morphological examination of the emerging adults (Forattini, 2002).

Adults were fed with $10 \%$ sucrose solution soaked in cotton balls, and twice a week, the females were fed with blood by placing anesthetized hamsters (Mesocricetus auratus) on top of the entomological cage for $30 \mathrm{~min}$, according to the protocol authorized by the Ethics Committee for the Use of Animals CEUA (CEUA, opinion No. 054/2018). Plastic cups with $100 \mathrm{ml}$ of water with partially immersed strip of filter paper were available for egg laying. The paper strips with laid eggs (F1) were dried for 2-3 days then placed in distilled water for hatching. The hatched larvae were again maintained in the same way as described before. Third instar larvae of the second generation (F2) were used for the larvicidal bioassays. All mosquitoes were kept under controlled conditions of temperature of $26 \pm 2{ }^{\circ} \mathrm{C}$ and relative humidity of $75 \pm 5 \%$, with a photoperiod of 12:12 h (light/dark), as recommended by the WHO (2005).

\section{Larvicidal Bioassays}

The selective and quantitative bioassays followed the criteria established by Dulmage et al. (1990) and the WHO (2005) with minor modifications. All bioassays were conducted under temperature, humidity, and photoperiod-controlled conditions, as previously mentioned.

Selective bioassays were performed in triplicate using $50 \mathrm{ml}$ plastic cups containing $10 \mathrm{ml}$ of distilled water, ten $3 \mathrm{rd}$ instar larvae, powdered rat food (Teklad Global 18\%) and $500 \mu \mathrm{g} / \mathrm{ml}$ of the fungal extract. All tested samples were solubilized in dimethyl sulfoxide (DMSO; Thermo Fisher Scientific). Mortality readings were recorded at 24,48 , and $72 \mathrm{~h}$ after exposure to the fungal extracts (Danga et al., 2014). The extracts that presented mortality equal to or greater than $90 \%$ in the selective bioassay were chosen to perform quantitative bioassays and determine lethal concentrations able to kill $50 \%\left(\mathrm{LC}_{50}\right)$ or $90 \%$ of the larvae $\left(\mathrm{LC}_{90}\right)$.
To determine $\mathrm{LC}_{50}$ and $\mathrm{LC}_{90}$ values, larvae were exposed to eight different concentrations of the fungal extracts, ranging from 0.01 to $250 \mu \mathrm{g} / \mathrm{ml}$. Each concentration was tested in quintuplicate with three repetitions. All assays were conducted in plastic cups with a capacity of $110 \mathrm{ml}$, containing $20 \mathrm{ml}$ of distilled water, powdered food, twenty 3 rd instar larvae and the quantity corresponding to each concentration of fungal extract tested. DMSO as the negative control and Temephos (Pestanal Sigma-Aldrich) as the positive control were used at the same concentrations as the extracts. DMSO (maximum volume of DMSO in the assay $-0.1 \mathrm{ml}$ ) did not cause mortality in any of the tested concentrations and Temephos $(500 \mu \mathrm{g} / \mathrm{ml})$ killed $100 \%$ of the larvae in the selective bioassay.

\section{Statistical Analysis}

The mortality data obtained in the bioassays were submitted to Probit analysis $p \leq 0.05$ (Finney, 1952), using the statistical software Polo Plus (LeOra Software, CA, United States; Haddad, 1998). Lethal concentrations and the confidence interval (95\% $\mathrm{CI})$ were calculated using the Lilliefors normality test $(\mathrm{K})$, analysis of variance (ANOVA), a multiple comparison test $(p \leq 0.05)$ and the Student's $t$ test using BioStat 5.3 for Windows software (Ayres et al., 2007).

\section{RESULTS}

In this study, 36 isolates belonging to 23 genera of fungi were analyzed regarding their ability to produce mosquito larvicidal compounds. Extracts from isolated strain were obtained from both mycelium and culture liquid medium fractions of the cultures. The growth time of the fungi until no glucose was detected in the medium ranged from 17 to 85 days. The $\mathrm{pH}$ of the cultures ranged from 6 to 7.5 in comparison to the $\mathrm{pH}$ of 5.5 in the control (non-inoculated medium). The extracts obtained from the liquid medium presented yielded between 82 and $724 \mathrm{mg}$, after extraction and drying procedures. Mycelium extracts from fungi strains 1132 and 1126 yielded 256 and $5872 \mathrm{mg}$, respectively, being the lowest and the highest obtained values (Table 1).

Seven mycelium extracts originating from fungi belonging to six genera (Aspergillus, Cladosporium, Fusarium, Diaporthe, Talaromyces, and Trichoderma) caused larval mortality from 3.3 to $43.3 \%$, and none presented mortality equal to or greater than $50 \%$ up to $72 \mathrm{~h}$ of exposure (Supplementary Table 1). Larvicidal activity equal to or greater than 50\% was observed in 15 of the 36 extracts of liquid medium; six liquid medium extracts belonging to five genera (Albifimbria, Aspergillus, Diaporthe, Emmia, and Sorocladium) killed 100\% of the larvae within $72 \mathrm{~h}$.

Eight extracts (from strains 1126, 1132, 1133, 1160, 1203, 1232, 1242 , and 1266) showed larvicidal activity equal to or greater than $50 \%$ at $24 \mathrm{~h}$, four $(1244,1246,1248$, and 1280$)$ resulted in $50 \%$ mortality only at $48 \mathrm{~h}$ and three extracts $(1184,1240$, and 1283 ) caused $50 \%$ mortality only at $72 \mathrm{~h}$ of exposure. Six extracts caused $100 \%$ larval mortality, three $(1160,1203$, and 1242) in 
TABLE 1 | Crude extracts of 36 fungi isolated from aquatic environments in the Amazonian municipalities of Coari and São Gabriel da Cachoeira used in the larvicidal tests against Aedes aegypti.

\begin{tabular}{|c|c|c|c|c|c|c|c|}
\hline \multirow[t]{2}{*}{ Tested lineage } & \multirow[t]{2}{*}{ GenBank accession numbers } & \multirow[t]{2}{*}{ Taxonomic identification } & \multirow[t]{2}{*}{ Cultivation time (days) } & \multirow[t]{2}{*}{$\mathrm{pH}$} & \multirow[t]{2}{*}{ Glucose } & \multicolumn{2}{|c|}{ Extract yield (mg) } \\
\hline & & & & & & Liquid medium & Mycelium \\
\hline 1160 & MZ781268 & Albifimbria lateralis ${ }^{C 1}$ & 50 & 6.5 & 0 & 120 & 820 \\
\hline 1283 & MZ781299 & Aspergillus hortai ${ }^{C 1}$ & 17 & 6.5 & 0 & 724 & 2577 \\
\hline 1126 & MZ781261 & Aspergillus sp. ${ }^{C 1}$ & 24 & 6.5 & 0 & 254 & 5872 \\
\hline 1169 & MZ781272 & Chrysoporthe sp. ${ }^{C 1}$ & 18 & 6.5 & 0 & 260 & 1624 \\
\hline 1132 & MZ781262 & Cladosporium sp. ${ }^{C 1}$ & 17 & 7 & 0 & 134 & 256 \\
\hline 1135 & MZ781264 & Cladosporium sp. ${ }^{C 1}$ & 17 & 6.5 & 0 & 177 & 334 \\
\hline 1098 & MZ781256 & Cytospora sp. ${ }^{\mathrm{C} 2}$ & 52 & 6 & 0 & 180 & 628 \\
\hline 1106 & MZ781257 & Cytospora sp. ${ }^{\mathrm{C} 2}$ & 41 & 6 & 0 & 443 & 3123 \\
\hline 1203 & MZ781276 & Diaporthe ueckerae ${ }^{\text {S4 }}$ & 41 & 6 & 0 & 249 & 2298 \\
\hline 1242 & MZ781281 & Diaporthe ueckerae ${ }^{\text {S4 }}$ & 28 & 7 & 0 & 152 & 872 \\
\hline 1232 & MZ781279 & Emmia sp. ${ }^{S 4}$ & 52 & 7.5 & 0 & 161 & 1128 \\
\hline 1248 & MZ781286 & Epicoccum latusicollum ${ }^{C 1}$ & 24 & 6.5 & 0 & 134 & 2564 \\
\hline 1240 & MZ781280 & Eutypella sp. ${ }^{S 4}$ & 41 & 6.5 & 0 & 221 & 3393 \\
\hline 1262 & MZ781291 & Fusarium oxysporum ${ }^{C 1}$ & 24 & 6.5 & 0 & 82 & 1559 \\
\hline 1280 & MZ781298 & Fusarium oxysporum ${ }^{C 1}$ & 24 & 6.5 & 0 & 98 & 959 \\
\hline 1085 & MZ781250 & Fusarium sp. ${ }^{S 4}$ & 27 & 7 & 0 & 90 & 1430 \\
\hline 1277 & MZ781297 & Hongkongmyces sp. s4 & 72 & 6.5 & 0 & 92 & 439 \\
\hline 1273 & MZ781296 & Hyphodermella sp. ${ }^{C 1}$ & 67 & 6 & 0 & 85 & 547 \\
\hline 1205 & MZ781277 & Hypomontagnella monticulosa ${ }^{C 1}$ & 72 & 8 & 0 & 258 & 750 \\
\hline 1082 & MZ781248 & Microsphaeropsis arundinis ${ }^{C 1}$ & 52 & 7.5 & 0 & 129 & 947 \\
\hline 1079 & MZ781246 & Nigrograna chromolaenae ${ }^{C 1}$ & 55 & 6.5 & 0 & 117 & 2840 \\
\hline 1123 & MZ781259 & Ochronis sp. ${ }^{C 1}$ & 28 & 6.5 & 0 & 149 & 540 \\
\hline 1083 & MZ781249 & Paraconiothyrium estuarinum ${ }^{C 1}$ & 28 & 6.5 & 0 & 129 & 2830 \\
\hline 1184 & MZ781274 & Paraconiothyrium estuarinum 54 & 63 & 6.5 & 0 & 140 & 2019 \\
\hline 1265 & MZ781293 & Paraconiothyrium estuarinum ${ }^{C 1}$ & 27 & 7 & 0 & 138 & 1850 \\
\hline 1080 & MZ781247 & Paraconiothyrium sp. ${ }^{s 4}$ & 28 & 6 & 0 & 132 & 1985 \\
\hline 1245 & MZ781283 & Penicillium citreosulfuratum ${ }^{S 4}$ & 35 & 6 & 0 & 250 & 838 \\
\hline 1266 & MZ781294 & Sorocladium sp. ${ }^{\mathrm{C} 2}$ & 80 & 6.5 & 0 & 92 & 645 \\
\hline 1089 & MZ781252 & Striaticonidium synnematum S3 & 31 & 7.5 & 0 & 205 & 1025 \\
\hline 1263 & MZ781292 & Talaromyces amestolkiae C2 & 18 & 6 & 0 & 250 & 3028 \\
\hline 1087 & MZ781251 & Talaromyces sp. ${ }^{\mathrm{C} 2}$ & 50 & 6.5 & 0 & 268 & 820 \\
\hline 1244 & MZ781282 & Talaromyces sp. ${ }^{S 4}$ & 80 & 6.5 & 0 & 262 & 901 \\
\hline 1246 & MZ781284 & Talaromyces sp. ${ }^{\mathrm{S} 4}$ & 17 & 6 & 0 & 127 & 1292 \\
\hline 1247 & MZ781285 & Trametes menziesii ${ }^{C 2}$ & 35 & 6 & 0 & 158 & 2870 \\
\hline 1133 & MZ781263 & Trichoderma atroviride ${ }^{\mathrm{C} 2}$ & 80 & 7.5 & 0 & 134 & 2109 \\
\hline \multirow[t]{2}{*}{1136} & MZ781265 & Trichoderma atroviride ${ }^{\mathrm{C} 2}$ & 85 & 6 & 0 & 223 & 334 \\
\hline & & Control (culture medium) & 80 & 5.5 & 2000 & 201 & - \\
\hline
\end{tabular}

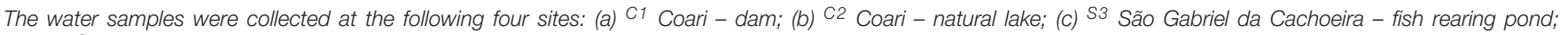

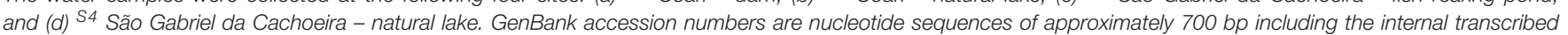

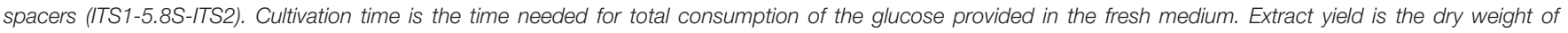
extracted metabolites.

less than $24 \mathrm{~h}$, two (1126 and 1266) at $48 \mathrm{~h}$ and one (1232) at $72 \mathrm{~h}$ (Figure 1).

Extracts with larvicidal activity equal to or greater than $90 \%$ (Albifimbria lateralis 1160, Aspergillus sp. 1126, Cladosporium sp. 1132, D. ueckerae 1203 and 1242, Emmia sp. 1232, Sorocladium sp. 1266, and Trichoderma atroviride 1133) were further studied and $\mathrm{LC}_{50}$ and $\mathrm{LC}_{90}$ values determined (Figure $\mathbf{1}$ and Supplementary Table 1).

Overall, the liquid medium extracts from Al. lateralis 1160 and D. ueckerae 1203 showed the best results, with highest mortality rates and lowest LC values. The extract of the strain 1160 ( Al. lateralis $)$ presented the lowest $\operatorname{LC}_{50}(0.268 \mu \mathrm{g} / \mathrm{ml})$ at $24 \mathrm{~h}$. The extract of the 1203 strain (D. ueckerae) had the lowest $\mathrm{LC}_{90}$ $(2.928 \mu \mathrm{g} / \mathrm{ml})$ at $24 \mathrm{~h}$. Furthermore, D. ueckerae 1203 extracts had the lowest $\operatorname{LC}_{50}(0.108 \mu \mathrm{g} / \mathrm{ml})$ and $\mathrm{LC}_{90}(0.894 \mu \mathrm{g} / \mathrm{ml})$ at $48 \mathrm{~h}$, and at $72 \mathrm{~h}$ with an $\mathrm{LC}_{50}$ of $0.062 \mu \mathrm{g} / \mathrm{ml}$ and an $\mathrm{LC}_{90}$ of $0.476 \mu \mathrm{g} / \mathrm{ml}$ (Table 2).

\section{DISCUSSION}

The public health importance of Ae. aegypti in tropical regions has attracted the attention of local authorities and the World Health Organization due to the wide geographical 
120

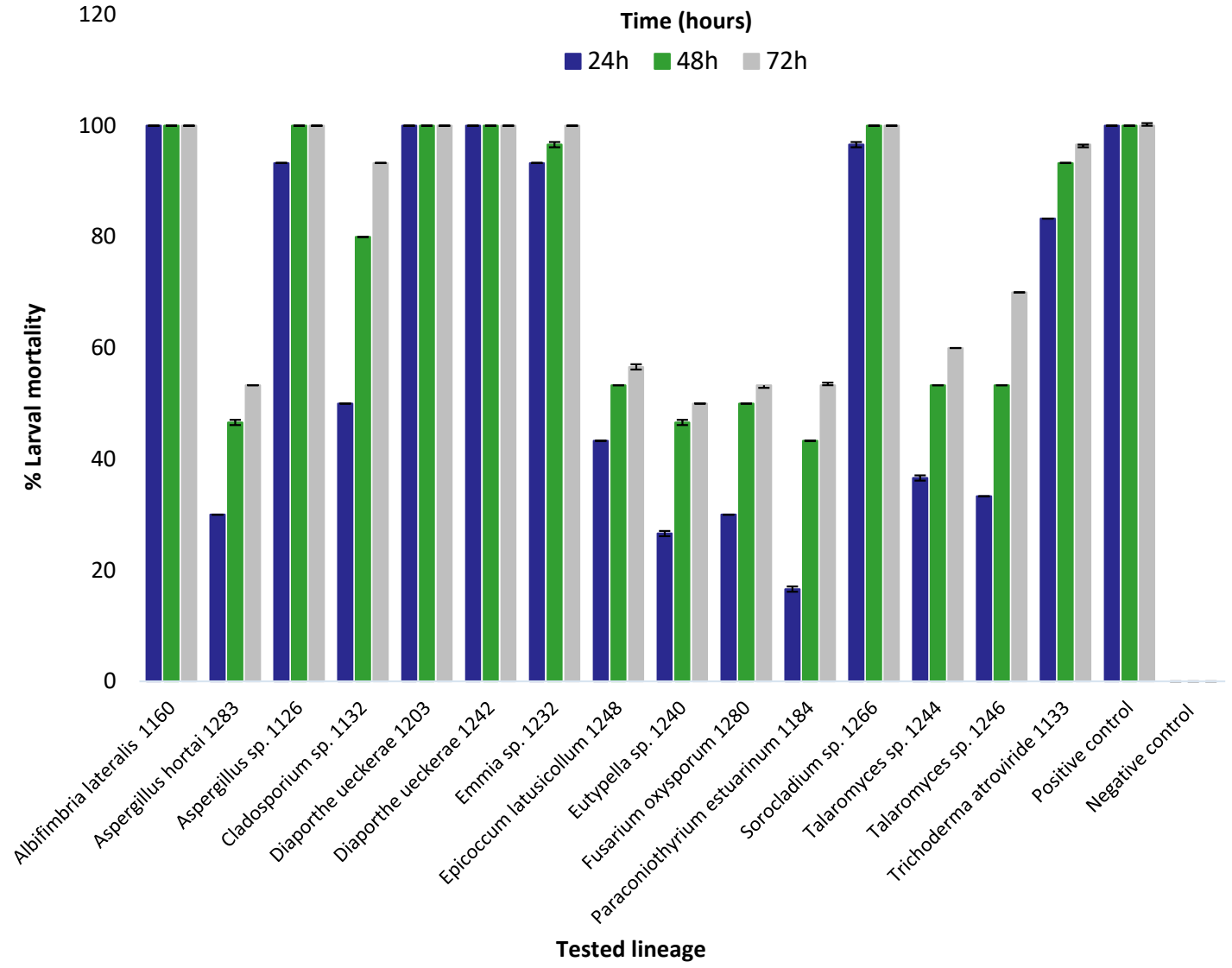

FIGURE 1 | Percentage of mortality of 3rd instar Aedes aegypti larvae exposed to liquid medium extracts obtained from strains of fungi isolated from Amazonian aquatic environments. Mortality was assessed after 24,48 , and $72 \mathrm{~h}$ of exposure to fungal extract at a concentration of $500 \mu \mathrm{g} / \mathrm{ml}$. Error bars represent standard deviation. Positive control (Temephos) and Negative control (dimethyl sulfoxide).

distribution and severity of diseases transmitted by these mosquitoes in the last decades, especially dengue, chikungunya, and Zika (Rodrigues-Alves et al., 2020). As such, there is a growing interest in new insecticides and larvicides capable of controlling this vector. Naturally derived insecticides have been pursued as potentially less toxic alternatives, aiming at reducing environmental pollution and preventing the selection of mosquitoes resistant to chemical insecticides (Al-Mekhlafi, 2017; Araújo et al., 2020).

For the control of Ae. aegypti, insecticides are frequently applied directly in natural bodies of water and/or artificial containers, usually located closely or kept inside human households. Therefore, the use of natural, potentially less-toxic, insecticides is desirable from both environmental and social perspectives. This work investigated for the first time extracts of fungi isolated from aquatic habitats of the Amazon region in order to identify fungal lineages that can produce larvicidal bioactive metabolites against Ae. aegypti.

Following the protocols described here, none of the mycelium extracts showed larvicidal activity resulting in mortality rates above $50 \%$ within $72 \mathrm{~h}$. However, 15 extracts from the liquid culture medium resulted in more than $50 \%$ mortality. Six killed
$100 \%$ of the larvae within $72 \mathrm{~h}$ and three of these were lethal in less than $24 \mathrm{~h}$, resembling the positive control Temephos. These results demonstrate that some of the isolated fungal strains secrete metabolites with larvicidal activity against Ae. aegypti.

The fungi tested in this study were subjected to the similar cultivation conditions. However, cultivation times varied for each fungal strain. To avoid differences in nutrient availability, we used total glucose consumption in the culture medium as determinant of the cultivation time length. Fungi growth styles and physical, chemical and biological factors, among others, influence development time and the production of bioactive metabolites (Kavanagh, 2011; Costa and Nahas, 2012). Speciesspecific traits explain the difference in cultivation time and biological activities among the isolated fungi studied in our work.

Mosquito larvicidal activities of the mycelial extracts and the liquid culture medium extracts, have been described for other fungi such as Stereum sp. (JO5289) (Chirchir et al., 2013), Beauveria bassiana (UNI 40) (Daniel et al., 2017), Trametes sp. (Waweru et al., 2017), Pestalotiopsis virgulata and Pycnoporus sanguineus (Bücker et al., 2013). However, the $\mathrm{LC}_{50}$ values revealed in our work are lower than those previously published, such as Metarhizium anisopliae 
TABLE 2 | Lethal larvicidal concentration of liquid culture medium extracts obtained from fungal strains against 3rd instar Aedes aegypti larvae.

\begin{tabular}{|c|c|c|c|c|c|}
\hline Tested lineage & $\mathrm{LC}_{50} \mu \mathrm{g} / \mathrm{ml}(\mathrm{Cl} 95 \%)$ & $\mathrm{LC}_{90} \mu \mathrm{g} / \mathrm{ml}(\mathrm{Cl} 95 \%)$ & $x^{2}$ & Df & Slope \pm SE \\
\hline \multicolumn{6}{|l|}{$24 \mathrm{~h}$} \\
\hline $\mathrm{Tp}$ & $0.025(0.003-0.063) \mathrm{ae}$ & $1.161(0.647-3.364) a$ & 6.9432 & 5 & $0.768 \pm 0.075$ \\
\hline 1126 & $0.872(0.200-3.956) a b d$ & $67.251(9.676-0.228 \mathrm{E}+06) \mathrm{ac}$ & 2.8009 & 2 & $0.679 \pm 0.066$ \\
\hline 1132 & 0.459 (0.043-1.057)abd & $74.117(11.419-0.152 \mathrm{E}+07) \mathrm{ac}$ & 3.9608 & 3 & $0.580 \pm 0.057$ \\
\hline 1133 & $0.463(0.367-0.586) \mathrm{bh}$ & $10.940(6.789-20.553) \mathrm{bc}$ & 1.000 & 6 & $0.933 \pm 0.060$ \\
\hline 1160 & ${ }^{*} 0.268(0.211-0.332) \mathrm{cdf}$ & $3.384(2.429-5.223) \mathrm{ac}$ & 2.995 & 5 & $1.164 \pm 0.061$ \\
\hline 1203 & $0.461(0.123-0.789) a d b$ & *2.928 (1.565-12.543)ac & 9.5913 & 3 & $1.597 \pm 0.065$ \\
\hline 1232 & $0.372(0.087-0.731) a d h$ & 26.304 (6.548-35.519)ac & 7.6254 & 4 & $0.693 \pm 0.054$ \\
\hline 1242 & 0.427 (0.029-0.839)ah & 67.918 (15.092-68.770)ac & 0.460 & 2 & $0.582 \pm 0.078$ \\
\hline 1266 & 1.904 (1.288-3.317)ef & 205.87 (53.346-272.74)ac & 0.961 & 4 & $0.630 \pm 0.053$ \\
\hline \multicolumn{6}{|l|}{$48 \mathrm{~h}$} \\
\hline $\mathrm{Tp}$ & 0.016 (0.002-0.038)a & $0.322(0.203-0.555) a$ & 5.3850 & 5 & $0.979 \pm 0.111$ \\
\hline 1126 & $0.337(0.191-0.489) a b$ & 6.293 (3.826-14.549)a & 1.922 & 2 & $1.009 \pm 0.069$ \\
\hline 1132 & $0.170(0.026-0.351) a b$ & $9.896(3.537-20.621) a$ & 6.3742 & 4 & $0.726 \pm 0.057$ \\
\hline 1133 & $0.142(0.050-0.253) a b$ & 3.261 (1.548-15.627)a & 12.854 & 5 & $0.942 \pm 0.063$ \\
\hline 1160 & $0.123(0.058-0.195) b$ & $1.106(0.666-2.735) \mathrm{a}$ & 13.497 & 5 & $1.345 \pm 0.083$ \\
\hline 1203 & ${ }^{*} 0.108(0.062-0.157) \mathrm{b}$ & ${ }^{*} 0.894$ (0.604-1.637)a & 8.1443 & 5 & $1.397 \pm 0.091$ \\
\hline 1232 & $0.206(0.030-0.412) b$ & 2.876 (1.302412-35.975)a & 15.328 & 4 & $1.119 \pm 0.074$ \\
\hline 1242 & $0.140(0.078-0.211) b$ & 12.095 (5.974-37.560)a & 1.821 & 5 & $0.662 \pm 0.056$ \\
\hline 1266 & $0.391(0.295-0.505) c$ & 10.825 (6.378-22.952)a & 3.846 & 5 & $0.889 \pm 0.091$ \\
\hline \multicolumn{6}{|l|}{$72 \mathrm{~h}$} \\
\hline Tp & $0.025(0.009-0.041) a$ & $0.141(0.107-0.185) \mathrm{a}$ & 2.532 & 5 & $1.694 \pm 0.280$ \\
\hline 1126 & 0.120 (0.053-0.198)a & 5.877 (3.351-15.174)a & 1.393 & 4 & $0.759 \pm 0.059$ \\
\hline 1132 & $0.079(0.033-0.132) a$ & $1.387(0.847-3.138) a$ & 7.5183 & 5 & $1.028 \pm 0.074$ \\
\hline 1133 & $0.070(0.023-0.126) a$ & 0.890 (0.531-2.237)a & 11.466 & 5 & $1.163 \pm 0.086$ \\
\hline 1160 & $0.088(0.055-0.122) a$ & $0.692(0.506-1.074) a$ & 5.2154 & 5 & $1.434 \pm 0.101$ \\
\hline 1203 & ${ }^{\star} 0.062(0.024-0.103) a$ & ${ }^{\star} 0.476$ (0.315-0.941)a & 10.131 & 5 & $1.453 \pm 0.121$ \\
\hline 1232 & $0.096(0.031-0.172) a$ & $1.292(0.713-4.132) a$ & 14.264 & 5 & $1.134 \pm 0.077$ \\
\hline 1242 & 0.088 (0.030-0.159)a & 2.119 (1.139-6.806)a & 9.3874 & 5 & $0.928 \pm 0.068$ \\
\hline 1266 & $0.180(0.101-0.269) a$ & $2.216(1.307-5.364) a$ & 9.8043 & 5 & $1.174 \pm 0.101$ \\
\hline
\end{tabular}

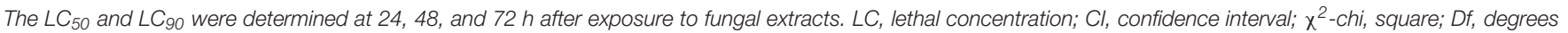

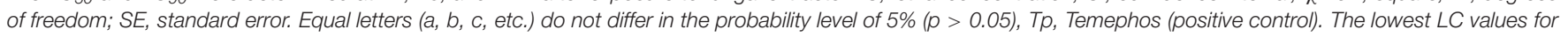
each time evaluated are shaded in gray and marked with *

$\left(\mathrm{LC}_{50}=59.83 \mu \mathrm{g} / \mathrm{ml}\right.$, Vivekanandhan et al., 2020), B. bassiana $\left(\mathrm{LC}_{50}=1.230 \mu \mathrm{g} / \mathrm{ml}\right.$, Daniel et al., 2017), and Aspergillus terreus $\left(\mathrm{LC}_{50}=80.407 \mu \mathrm{g} / \mathrm{ml}\right.$, Ragavendran and Natarajan, 2015), indicating the potency of the metabolites obtained from the strains tested in our study.

It is worth noting that to date there have been no reports of biological activities against insect species of metabolites produced by fungal strains of the species Al. lateralis, $D$. ueckerae, and Emmia sp. For the first time, lineages of these species of fungi with larvicidal activity against Ae. aegypti have been identified.

The genus Albifimbria consists of four species, i.e., Al. lateralis, Albifimbria terrestris, Albifimbria verrucaria, and Albifimbria viridis, which are usually found in soil, leaves, fruits, and in the air (Lombard et al., 2016). The species Albifimbria lateralis (Lombard et al., 2016) has been recently described and needs better investigation regarding the production of secondary metabolites, though our investigation indicates promising applications of this fungus species in vector control. Metabolites produced by Al. verrucaria exhibit antimicrobial activities (Zou et al., 2011) and bioherbicidal activities (Walker and Tilley, 1997) and are considered to be a potential biocontrol agent against the fungus Botrytis cinerea in grapes (Li et al., 2019).

The species $D$. ueckerae was described by Udayanga et al. (2015). Its occurrence in Brazil was identified by Soares et al. (2018) who isolated this species of fungus from Costus spiralis (Jacq.) Roscoe (Costaceae), a plant native to the Amazon region used in traditional medicine. Fungal species of the genus Diaporthe are known to be a rich source of secondary metabolites (Chepkirui and Stadler, 2017).

Currently, 106 compounds derived from Diaporthe exhibiting biological activities, such as cytotoxic, antifungal, antibacterial, antiviral, antioxidant, anti-inflammatory, phytotoxic, antiparasitic, and herbicidic activities, have been studied (Ash et al., 2010; Meepagala et al., 2018; Xu et al., 2021). Two cyclohexeneoxidediones, phyllostine acetate (1) and phyllostine (2), from the fungus Diaporthe miriciae, showed insecticidal activity against Plutella xylostella larvae (Ratnaweera et al., 2020). Meepagala et al. (2018) isolated a compound from the liquid medium extract of Diaporthe eres, identified as 3,4-dihydro-8-hydroxy-3,5-dimethylisocoumarin (1), which has larvicidal activity against $A$ e. aegypti. 
In addition, other fungi from different genera such as Beauveria, Fusarium, Metarhizium, Neosartorya, and Paecilomyces, also produce compounds with insecticidal activity such as beauvericin, gliotoxin, enniatin, oosporein, destruxins, cytochalasins, etc (Vyas et al., 2007; Masi et al., 2017; Berestetskiy and $\mathrm{Hu}, 2021$ ).

\section{CONCLUSION}

This study is the first to evaluate aquatic fungi strains from the Amazon for their ability of producing mosquito larvicidal metabolites. Our findings open opportunities for the development of new larvicides that may be used as mosquito control agents. Crude fungal extracts, such as those studied here, are a complex mixture of different classes of molecules. The process of fractionation and purification of raw extracts guided by bioactivity (Chirchir et al., 2013) is necessary for the isolation and characterization of the chemical compounds responsible for the larvicidal activities observed in our work. Further studies are needed to characterize the active larvicidal metabolites produced by these fungi and define their mechanisms of action.

\section{DATA AVAILABILITY STATEMENT}

The original contributions presented in the study are included in the article/Supplementary Material, further inquiries can be directed to the corresponding authors.

\section{AUTHOR CONTRIBUTIONS}

MO, WT, ADS, and AQS designed the study. MO, ADS, and AQS performed the production of fungal extracts, analyzed the

\section{REFERENCES}

Al-Mekhlafi, F. A. (2017). Larvicidal activity of some fungal extracts on Aedes caspius and Culex pipiens (Diptera: Culicidae). Entomol. Res. 47, 388-393. doi: 10.1111/1748-5967.12235

Araújo, I. F., Loureiro, H. A., Marinho, V. H. S., Neves, F. B., Sarquis, R. S. F., Faustino, S. M. M., et al. (2020). Larvicidal activity of the methanolic, hydroethanolic and hexanic extracts from Acmella oleracea, solubilized with silk fibroin, against Aedes aegypti. Biocatal. Agric. Biotechnol. 24:101550. doi: 10.1016/j.bcab.2020.101550

Ash, G. J., Stodart, B., Sakuanrungsirikul, S., Anschaw, E., Crump, N., Hailstones, D., et al. (2010). Genetic characterization of a novel Phomopsis sp., a putative biocontrol agent for Carthamus lanatus. Mycologia 102, 54-61. doi: 10.3852/ 08-198

Ayres, M., Ayres, J. R. M., Ayres, D. L., and dos Santos, A. (2007). Aplicações Estatísticas Nas Áreas Das Ciências Biológicas e Médicas. Belém: BioEstat.

Berestetskiy, A., and Hu, Q. (2021). The chemical ecology approach to reveal fungal metabolites for arthropod pest management. Microorganisms 9:1379. doi: 10.3390/microorganisms 9071379

Bhakuni, D. S., and Rawat, D. S. (2006). Bioactive Marine Natural Products. Berlin: Springer Science \& Business Media.

Bücker, A., Bucker, N. C. F., Souza, A. Q., Gama, A. M., Rodrigues-Filho, E., Costa, F. M., et al. (2013). Larvicidal effects of endophytic and basidiomycete fungus extracts on Aedes and Anopheles larvae (Diptera, Culicidae). Rev. Soc. Bras. Med. Trop. 46, 411-419. doi: 10.1590/0037-8682-00632013 results, and wrote the manuscript. $\mathrm{MO}$ and $\mathrm{RK}$ reared mosquitoes and carried out bioassays. MO, GS, OM, OT, ADS, and AQS supervised and finalized the manuscript. All authors read and approved the final manuscript.

\section{FUNDING}

This study was financed in part by the Coordenação de Aperfeiçoamento de Pessoal de Nível Superior Brazil (CAPES) - Finance Code 001, by the project Pró-Amazônia: Biodiversidade e Sustentabilidade (process number 23038.009442/2013-12) and FAPEAM. This study is part of the doctoral thesis of $\mathrm{MO}$ (Universidade Federal do Amazonas).

\section{ACKNOWLEDGMENTS}

We would like to thank the Graduate Program in Biodiversity and Biotechnology - PPG-BIONORTE, for MO's thesis opportunity, as also the Embrapa Western Amazon/EMBRAPA, Malaria and Dengue Laboratory of the National Institute for Amazonian Research - INPA, and LabMicrA laboratory of the Central Analítica - CAM/ UFAM, for the necessary spaces and equipment to the development of the work.

\section{SUPPLEMENTARY MATERIAL}

The Supplementary Material for this article can be found online at: https://www.frontiersin.org/articles/10.3389/fmicb. 2021.743246/full\#supplementary-material

Chepkirui, C., and Stadler, M. (2017). The genus Diaporthe: a rich source of diverse and bioactive metabolites. Mycol. Prog. 16, 477-494. doi: 10.1007/s11557-0171288-y

Chirchir, D. K., Ouma, R. B. O., Cheplogoi, P. K., and Omolo, J. O. (2013). Larvicidal activity of extracellular secondary metabolites from a Stereum species Hill ex Pers.(JO5289) against the dengue fever mosquito, Aedes aegypti (Linn)(Diptera: Culicidae). Afr. J. Biotechnol. 12, 6302-6309.

Consoli, R. A. G. B., and Oliveira, R. L. (1994). Principais Mosquitos de Importância Sanitária no Brasil. Available online at: http://books.scielo.org/id/th (accessed November 15, 2020).

Costa, B. D. O., and Nahas, E. (2012). Growth and enzymatic responses of phytopathogenic fungi to glucose in culture media and soil. Braz. J. Microbiol. 43, 332-340. doi: 10.1590/S1517-838220120001000039

Danga, Y. S. P., Nukenine, E. N., Younoussa, L., and Esimone, C. O. (2014). Phytochemicals and larvicidal activity of Plectranthus glandulosus (Lamiaceae) leaf extracts against Anopheles gambiae, Aedes aegypti and Culex quinquefasciatus (Diptera: Culicidae). Int. J. Pure Appl. Zool. 2, 160-171.

Daniel, J. F. S., Silva, A. A., Nakagawa, D. H., Medeiros, L. S., Carvalho, M. G., Tavares, L. J., et al. (2017). Larvicidal activity of Beauveria bassiana extracts against Aedes aegypti and identification of Beauvericins. J. Braz. Chem. Soc. 28, 1003-1013. doi: 10.21577/0103-5053.20160253

de Oliveira Barbosa Bitencourt, R., Reis Dos Santos Mallet, J., Mesquita, E., Silva Gôlo, P., Fiorotti, J., Rita Elias Pinheiro Bittencourt, V., et al. (2021). Larvicidal activity, route of interaction and ultrastructural changes in Aedes aegypti exposed to entomopathogenic fungi. Acta Trop. 213:105732. doi: 10. 1016/j.actatropica.2020.105732 
Dugan, F. M. (2006). The Identification of Fungi. An Illustrated Introduction with Keys, Glossary, and Guide to Literature. Saint Paul, MIN: The American Phytopathological Society.

Dulmage, H. T., Yousten, A. A., Singer, S., and Lacey, L. A. (1990). Guidelines for Production of Bacillus Thuringiensis $\mathrm{H}-14$ and Bacillus Sphaericus. Available online at: https://apps.who.int/iris/handle/10665/61645 (accessed May 18, 2020).

Finney, D. J. (1952). Probit Analysis: A Statistical Treatment of the Sigmoid Response Curve. Cambridge: Cambridge university press.

Forattini, O. P. (2002). Culicidologia Médica, Vol. 2. São Paulo: EDUSP.

Haddad, M. D. L. (1998). Utilização do Polo-PC Para Análise de Probit. Controle Microbiano de Insetos. Piracicaba: FEALQ, 999-1013.

Hanlin, R. T., and Ulloa, M. (1988). Atlas of Introductory Mycology, 2nd Edn. Winston-Salem: Hunter Textbooks. Inc.

Hawksworth, D. L., Kirk, P. M., Sutton, B. C., and Pegler, D. N. (1995). Ainsworth \& Bisby's Dictionary of the Fungi, 8th Edn. Oxfordshire: Oxford University Press.

Imhoff, J. F. (2016). Natural products from marine fungi-still an underrepresented resource. Mar. Drugs 14:19. doi: 10.3390/md14010019

Kavanagh, K. (ed.) (2011). Fungi: biology and applications, 2nd Edn. Hoboken, NJ: John Wiley \& Sons.

Li, Z., Chang, P., Gao, L., and Wang, X. (2019). The endophytic fungus albifimbria verrucaria from wild grape as an antagonist of botrytis cinerea and other grape pathogens. Phytopathology 110, 843-850. doi: 10.1094/PHYTO-09-19-0347-R

Lombard, L., Houbraken, J., Decock, C., Samson, R. A., Meijer, M., Réblová, M., et al. (2016). Generic hyper-diversity in Stachybotriaceae. Persoonia 36, 156-246. doi: 10.3767/003158516X691582

Malhi, Y., Roberts, J. T., Betts, R. A., Killeen, T. J., Li, W., and Nobre, C. A. (2008). Climate change, deforestation, and the fate of the amazon. Science 319, 169-172. doi: 10.1126/science.1146961

Masi, M., Cimmino, A., Tabanca, N., Becnel, J. J., Bloomquist, J. R., and Evidente, A. (2017). A survey of bacterial, fungal and plant metabolites against Aedes aegypti (Diptera: Culicidae), the vector of yellow and dengue fevers and Zika virus. Open Chem. 15, 156-166.

Meepagala, K. M., Estep, A. S., Clausen, B. M., and Becnel, J. J. (2018). Mosquitocidal activity of a naturally occurring isochroman and synthetic analogs from the plant pathogenic fungus, diaporthe eres against Aedes aegypti (Diptera: Culicidae). J. Med. Entomol. 55, 969-974. doi: 10.1093/jme/tjy016

Oliveira, M. R. (2021). Potencial da Biodiversidade Fúngica Cultivável de Habitats Aquáticos da Região Amazônica Para o Controle de Doenças Infecciosas. Ph.D. thesis. Manaus: Universidade Federal do Amazonas.

PAHO (2020). Pan American Health Organization/World Health Organization. Epidemiological Update: Dengue. Washington, DC: PAHO.

Possas, C., Brasil, P., Marzochi, M. C., Tanuri, A., Martins, R. M., Marques, E. T., et al. (2017). Zika puzzle in Brazil: peculiar conditions of viral introduction and dissemination - a review. Mem. Inst. Oswaldo Cruz 112, 319-327. doi: 10.1590/0074-02760160510

Ragavendran, C., and Natarajan, D. (2015). Insecticidal potency of Aspergillus terreus against larvae and pupae of three mosquito species Anopheles stephensi, Culex quinquefasciatus, and Aedes aegypti. Environ. Sci. Pollut. Res. 22, 17224 17237. doi: 10.1007/s11356-015-4961-1

Ratnaweera, P. B., Jayasundara, J. M. N. M., Herath, H. H. M. S. D., Williams, D. E., Rajapaksha, S. U., Nishantha, K. M. D. W. P., et al. (2020). Antifeedant, contact toxicity and oviposition deterrent effects of phyllostine acetate and phyllostine isolated from the endophytic fungus Diaporthe miriciae against Plutella xylostella larvae. Pest. Manag. Sci. 76, 1541-1548. doi: 10.1002/ps.5673

Rodrigues-Alves, M. L., Melo-Júnior, O. A., de, O., Silveira, P., Mariano, R. M., da, S., et al. (2020). Historical perspective and biotechnological trends to block arboviruses transmission by controlling Aedes aegypti mosquitos using different approaches. Front. Med. 7:275. doi: 10.3389/fmed.2020.00275

Saúde, M. D., and Saúde, S. (2016). Boletim Epidemiológico. Monitoramento dos Casos de Dengue, Febre de Chikungunya e Febre Pelo Vírus Zika até a Semana Epidemiológica 52, 2015. Available online at: https://antigo.saude. gov.br/images/pdf/2016/janeiro/15/svs2016-be003-dengue-se52.pdf (accessed November 18, 2020).

Saúde, M. D., and Saúde, S. (2018). Boletim Epidemiológico 47: Situação Epidemiológica da Infecção Pelo Vírus Zika no Brasil, de 2015 a 2017. Available online at: https://antigo.saude.gov.br/images/pdf/2018/novembro/12/ 2018-034.pdf (accessed November 15, 2020).
Seetharaman, P. K., Chandrasekaran, R., Gnanasekar, S., Chandrakasan, G., Gupta, M., Manikandan, D. B., et al. (2018). Antimicrobial and larvicidal activity of eco-friendly silver nanoparticles synthesized from endophytic fungi Phomopsis liquidambaris. Biocat. Agric. Biotechnol. 16, 22-30. doi: 10.1016/j.bcab.2018.07. 006

Soares, D. A., Oliveira, D. P., Santos, T. T., Marson, P. G., and Pimenta, R. S. (2018). Multiloci identification of Diaporthe fungi isolated from the medicinal plant Costus spiralis (Jacq.) Roscoe (Costaceae). J. Appl. Microbiol. 125, 172-180. doi: 10.1111/jam.13769

Souza, A. Q. L., Souza, A. D. L., Astolfi Filho, S., Pinheiro, M. L. B., Sarquis, M. I., de, M., et al. (2004). Antimicrobial activity of endophytic fungi isolated from amazonian toxic plants: Palicourea longiflora (aubl.) rich and Strychnos cogens bentham. Acta Amazon. 34, 185-195.

Udayanga, D., Castlebury, L. A., Rossman, A. Y., Chukeatirote, E., and Hyde, K. D. (2015). The Diaporthe sojae species complex: phylogenetic re-assessment of pathogens associated with soybean, cucurbits and other field crops. Fungal Biol. 119, 383-407. doi: 10.1016/j.funbio.2014.10.009

Vivekanandhan, P., Bedini, S., and Shivakumar, M. S. (2020). Isolation and identification of entomopathogenic fungus from Eastern Ghats of South Indian forest soil and their efficacy as biopesticide for mosquito control. Parasitol. Int. 76:102099. doi: 10.1016/j.parint.2020.102099

Vyas, N., Dua, K. K., and Prakash, S. (2007). Efficacy of Lagenidium giganteum metabolites on mosquito larvae with reference to nontarget organisms. Parasitol. Res. 101, 385-390. doi: 10.1007/s00436-007-0496-9

Walker, H. L., and Tilley, A. M. (1997). Evaluation of an isolate of Myrothecium verrucaria from sicklepod (Senna obtusifolia) as a potential mycoherbicide agent. Biol. Control 10, 104-112. doi: 10.1006/bcon.1997.0559

Waweru, A. W., Omolo, J. O., Cheplogoi, P. K., and Njue, A. W. (2017). Mosquito larvicidal trihydroxylindene derivative from submerged cultures of trametes species. Afr. J. Biotechnol. 16, 1457-1460.

WHO (2005). Guidelines for Laboratory and Field Testing of Mosquito Larvicides. Available online at: https://apps.who.int/iris/handle/10665/69101 (accessed October 12, 2020).

WHO (2020). Dengue and Severe Dengue. Available online at: https://www.who.int/ news-room/fact-sheets/detail/dengue-and-severe-dengue (accessed April 20, 2021)

Xu, T.-C., Lu, Y.-H., Wang, J.-F., Song, Z.-Q., Hou, Y.-G., Liu, S.-S., et al. (2021). Bioactive secondary metabolites of the genus Diaporthe and Anamorph Phomopsis from terrestrial and marine habitats and endophytes: 2010-2019. Microorganisms 9:217. doi: 10.3390/microorganisms9 020217

Zanotto, P. M. A., and Leite, L. C. C. (2018). The challenges imposed by dengue, zika, and chikungunya to Brazil. Front. Immunol. 9:1964. doi: 10.3389/fimmu. 2018.01964

Zara, A. L., de, S. A., Santos, S. M. D., Fernandes-Oliveira, E. S., Carvalho, R. G., and Coelho, G. E. (2016). [Aedes aegypti control strategies: a review]. Epidemiol. Serv. Saude 25, 391-404. doi: 10.5123/S1679-49742016000200017

Zou, X., Niu, S., Ren, J., Li, E., Liu, X., and Che, Y. (2011). Verrucamides AD, antibacterial cyclopeptides from Myrothecium verrucaria. J. Nat. Prod. 74, 1111-1116. doi: $10.1021 / \mathrm{np} 200050 \mathrm{r}$

Conflict of Interest: The authors declare that the research was conducted in the absence of any commercial or financial relationships that could be construed as a potential conflict of interest.

Publisher's Note: All claims expressed in this article are solely those of the authors and do not necessarily represent those of their affiliated organizations, or those of the publisher, the editors and the reviewers. Any product that may be evaluated in this article, or claim that may be made by its manufacturer, is not guaranteed or endorsed by the publisher.

Copyright (C) 2021 de Oliveira, Katak, da Silva, Marinotti, Terenius, Tadei, de Souza and de Souza. This is an open-access article distributed under the terms of the Creative Commons Attribution License (CC BY). The use, distribution or reproduction in other forums is permitted, provided the original author $(s)$ and the copyright owner(s) are credited and that the original publication in this journal is cited, in accordance with accepted academic practice. No use, distribution or reproduction is permitted which does not comply with these terms. 